\title{
Ret Oncogene Activation in Human Thyroid Neoplasms Is Restricted to the Papillary Cancer Subtype
}

\author{
Massimo Santoro," Francesca Carlomagno," lan D. Hay, ${ }^{\ddagger}$ Marie A. Herrmann,; Michele Grieco, ${ }^{*}$ Rosamarina Melillo, \\ Marco A. Pierotti," Italia Bongarzone," Giuseppe Della Porta," Nicole Berger," Jean Louis Peix," Christian Paulin," \\ Nicole Fabien," Giancarlo Vecchio," Robert B. Jenkins, ${ }^{*}$ and Alfredo Fusco" \\ ${ }^{*}$ Centro di Endocrinologia ed Oncologia Sperimentale del CNR, \% Dipartimento di Biologia e Patologia Cellulare e Molecolare, II \\ Facoltà di Medicina e Chirurgia, Università di Napoli, 80131 Naples, Italy; ${ }^{\ddagger}$ Divisions of Endocrinology and Internal Medicine and \\ Laboratory Genetics, Mayo Clinic, Rochester, Minnesota 55905; ' Divisione di Oncologia Sperimentale A, Istituto Nazionale Tumori, \\ 20133 Milan, Italy; "Laboratoire d'Anatomie Pathologique, Service de Chirurgie, Hôpital de L'Antiquaille, 69321 Lyon Cedex 05 \\ France; Laboratoire de Cytologie, Hôpital Jules Courmont 69310, Pierre Benite, France; and 'Dipartimento di Medicina Sperimentale \\ e Clinica, Facoltà di Medicina e Chirurgia di Catanzaro, Università degli Studi di Reggio Calabria, 88100 Catanzaro, Italy
}

\begin{abstract}
We have recently reported the activation of a new oncogene in human papillary thyroid carcinomas. This oncogene, papillary thyroid carcinoma (PTC), is a novel rearranged version of the ret tyrosine-kinase protooncogene. Thyroid neoplasms include a broad spectrum of malignant tumors, ranging from well-differentiated tumors to undifferentiated anaplastic carcinomas. To determine the frequency of ret oncogene activation, we analyzed 286 cases of human thyroid tumors of diverse histologic types. We found the presence of an activated form of the ret oncogene in $33(19 \%)$ of 177 papillary carcinomas. By contrast, none of the other 109 thyroid tumors, which included 37 follicular, 15 anaplastic, and 18 medullary carcinomas, and 34 benign lesions, showed ret activation. (J. Clin. Invest. 1992. 89:15171522.) Key words: carcinoma $\bullet$ gene rearrangement $\bullet$ ret protooncogene • tyrosine kinase • PTC
\end{abstract}

\section{Introduction}

There is growing evidence that tumor development and progression may result from a series of genetic alterations that affect the normal mechanisms controlling cell proliferation (1). Molecular events that have been identified include inactivation of tumor-suppressor genes (2), as well as activating mutations of cellular protooncogenes (3). In some cases, specific oncogenes are altered in specific tumors. Thus, the N-myc and c$e r b-\mathrm{B} 2 /$ neu oncogenes are amplified in neuroblastomas (4) and in breast carcinomas (5), respectively. Similarly, c-myc and c$a b l$ are involved in the chromosomal translocations which characterize Burkitt's lymphoma and chronic myelogenous leukemia (3), respectively. Moreover, there is some evidence suggesting a specificity for activation of particular ras gene family members in some forms of cancer: e.g., K-ras in lung, colon, and pancreas carcinomas (6-8), and N-ras in acute myeloid leukemia (9).

Address correspondence and reprint requests to Dr. Massimo Santoro, Centro di Endocrinologia ed Oncologia, Sperimentale del CNR, Universita di Napoli, Via S. Pansini 5, 80131 Naples, Italy.

Received for publication 9 September 1991 and in revised form 11 December 1991.

J. Clin. Invest.

(C) The American Society for Clinical Investigation, Inc.

$0021-9738 / 92 / 05 / 1517 / 06 \$ 2.00$

Volume 89, May 1992, 1517-1522
The thyroid provides an attractive model to study the steps that are involved in the neoplastic process. Most thyroid neoplasms originate from a single cell type, the thyroid follicular cell. However, they comprise a broad spectrum of tumors with different phenotypic characteristics and variable biological and clinical behavior: i.e., from the benign colloid adenomas, through the slowly progressive differentiated papillary and follicular carcinomas, to the invariably fatal anaplastic carcinomas (10). Papillary and follicular carcinomas are considered to be two different biological entities. Typically, papillary carcinoma is multifocal. It generally metastasizes to regional lymph nodes, and has been associated with previous radiation exposure. Conversely, follicular carcinoma is solitary and encapsulated. It invades blood vessels and spreads often to bones; its highest incidence has been reported from endemic goitrous areas (10). It seems probable that the differences observed in biological behavior could be explained by the involvement of different genetic events in the pathogenesis of these two differing follicular cell-derived malignancies.

We have recently demonstrated the frequent activation of a new oncogene in human papillary thyroid carcinomas (11-13). We have shown that this oncogene, named papillary thyroid carcinoma (PTC), ${ }^{1}$ is the product of the recombination of the tyrosine-kinase domain of the ret protooncogene with a thus far uncharacterized gene that we have named H4 (13). In addition, we have observed that an inversion (10)(q11.2-q21) is present in a significant number of papillary thyroid carcinomas (14). The ret and $\mathrm{H} 4$ genes are both localized on the long arm of the chromosome $10(15-17)$, and we have demonstrated that at least in four cases, the inversion on chromosome 10 determines their fusion (17a).

To confirm the frequency of activation of ret in papillary tumors in a wider collection of samples, and to ascertain what role ret activation may play in the pathogenesis of nonpapillary thyroid tumors, we have analyzed 286 human thyroid neoplasms collected at the Mayo Clinic, Rochester, Minnesota, at the Hospitals of Lyon, France, at the Istituto Nazionale Tumori of Milan, and at the II Medical School of Naples, Italy. In this study we demonstrate that ret oncogene is frequently activated only in the papillary histotype of thyroid carcinomas. From these findings, we would suggest that ret activation may represent a specific genetic event that may be of value in the differential diagnosis of papillary thyroid cancer in man.

1. Abbreviations used in this paper: PCR, polymerase chain reaction; PTC, papillary thyroid carcinoma. 


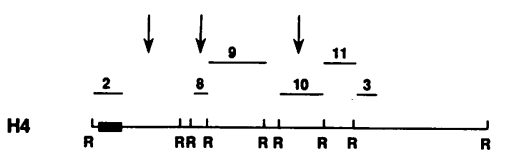

RET

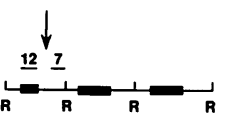

$3 \mathbf{K b}$

$R=$ EcoRI

Figure 1. Schematic representation of the genomic restriction maps of the $\mathrm{H} 4$ and protoret genes. Closed boxes represent the approximate positions of the coding sequences. The arrows mark the positions of the previously described breakpoints in the two genes (13). Above the maps are illustrated the DNA probes used in this study. They correspond to the probes indicated in Fig. 1 of reference 13. Probe 12 is a 1.8-kbp BamHI restriction fragment. The restriction sites shown are R: EcoRI.

\section{Methods}

DNA extraction and Southern blot analysis. The tumor samples were frozen in liquid nitrogen and stored frozen until DNA extractions were performed. The specimens obtained from the Mayo Clinic were evaluated for their content in tumoral cells. A certain degree of contamination by normal cells was observed. However, DNA extractions were performed from those sections containing not less than $70 \%$ of neoplastic cells. High molecular weight DNA extraction from tumors and Southern blot analyses were performed, according to standard procedures (18). Briefly, $10 \mu \mathrm{g}$ of DNA were digested, as recommended by the enzyme manufacturer (Amersham Corp., Arlington Heights, IL; Promega Biotec., Madison, WI), electrophoresed through $0.8 \%$ agarose, transferred to nylon filters (Hybond-N; Amersham Corp.), and hybridized to ${ }^{32} \mathrm{P}$-labeled probes by the random oligonucleotide primer kit (Amersham Corp.). Hybridization and washings were carried out under stringent conditions, as previously described (13). Autoradiography was performed by using Kodak XAR films at $-70^{\circ} \mathrm{C}$ for $1-7 \mathrm{~d}$ with intensifying screens.

Transfection assay. The DNAs extracted from tumor specimens were transfected onto $\mathrm{NIH} / 3 \mathrm{~T} 3$ cells by the calcium phosphate coprecipitation technique, following a modified version of the protocol of Chen and Okayama, as previously described (12). Foci of transformed cells were evaluated after 2-3 wk.

$R N A$ analysis and polymerase chain reaction (PCR). RNA extraction was performed, as previously described (19). The RNA amplification was done following the method described by E. S. Kawasaki (20), starting from $5 \mu \mathrm{g}$ of total RNA. The sequences of the sense H4-(196213) and the antisense $R E T$ (544-561)-related primers were as follows: H4: 5'-ATTGTCATCTCGCCGTTC-3'; RET: 5'-CTGCTTCAGGACGTTGAA-3'. The break-point is at nucleotides 351-352. The expected amplified product of the PTC mRNA is $363 \mathrm{bp}$ long.

\section{Results}

Southern blot analysis. The ret protooncogene encodes a protein structurally related to transmembrane receptors with a cytoplasmic tyrosine-kinase domain (21-23). We have demonstrated that the truncation of the $\mathrm{NH}_{2}$-terminal region leads to its activation in thyroid papillary carcinomas. This rearrangement occurs in an intronic sequence that lies between the TK and the transmembrane-encoding domain of the ret protooncogene, and it is possible to detect this rearrangement by Southern blot analysis of the tumor DNA (13). Fig. 1 shows a schematic representation of the genomic restriction maps of ret and $\mathrm{H} 4$, and of the rearrangements between the two genes previously reported (13).

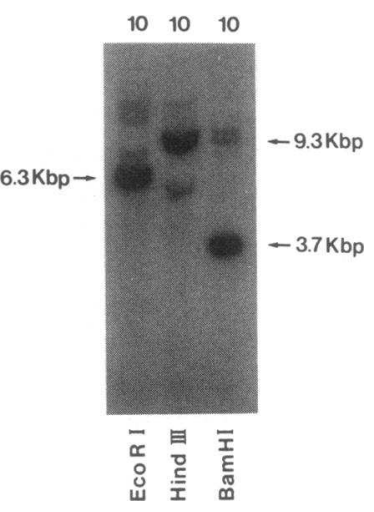

Figure 2. Examples of ret rearrangement in papillary thyroid carcinomas collected at the Hospitals of Lyon. Southern blot analysis of DNA extracted from the neoplastic specimens. $10 \mu \mathrm{g}$ of DNA were digested with EcoRI, BamHI, or HindIII restriction enzymes (Amersham Corp.), transferred to nylon filters (Hybond-N; Amersham Corp.) and hybridized to a 1.0-kbp BamHI-BglII ret-specific probe. The arrows indicate the size of the normal fragments. (Lanes 9, 10, 14, 42, 53, and 55) DNAs extracted from different tumoral samples. (Lane $N$ ) DNA extracted from normal human tissue. A partial restriction map of the region of the ret gene analyzed and the probe used (shaded area) are shown. 
Here, we report the analysis of 286 neoplastic thyroid samples for ret activation. This analysis has been performed by probing Southern blots with a 1-kbp BglII-BamHI DNA fragment. This fragment is able to identify the region within the ret gene where rearrangement occurs (Probe 7 of Fig. 1) (13). This probe hybridizes to a 6.3-kbp EcoRI, a 3.7-kbp BamHI, and a 9.3-kbp HindIII restriction fragment in normal human DNA (see map on Fig. 2). We found that 33 (11.5\%) out of 286 samples showed adjunctive rearranged bands, and this result was demonstrable with at least three different restriction enzymes (examples are in Figs. 2 and 3). In some cases, the rearranged band had a decreased intensity with respect to the normal one (for example, lane 10, Fig. 2). This is most likely due to contamination of the tumoral specimen by normal surrounding tissue. The possibility that the rearrangement might involve only a fraction of the neoplastic cells is currently under investigation by using the in situ RNA hybridization technique.

The rearrangement was specific for the papillary histotype; it was present in 11 out of 65 papillary samples $(16.9 \%)$ collected at the Mayo Clinic, 8 out of $70(11.4 \%)$ from Lyon, and 14 out of 42 (33.3\%) from Milan. We did not find any rearrangement in the 37 follicular, 15 anaplastic, and 18 medullary carcinomas, nor in the 34 benign lesions that we have analyzed (Table I).

Transfection assay. We evaluated the transforming activity of the 14 samples collected at the Istituto Nazionale Tumori of Milan which already scored positive for ret rearrangement. All
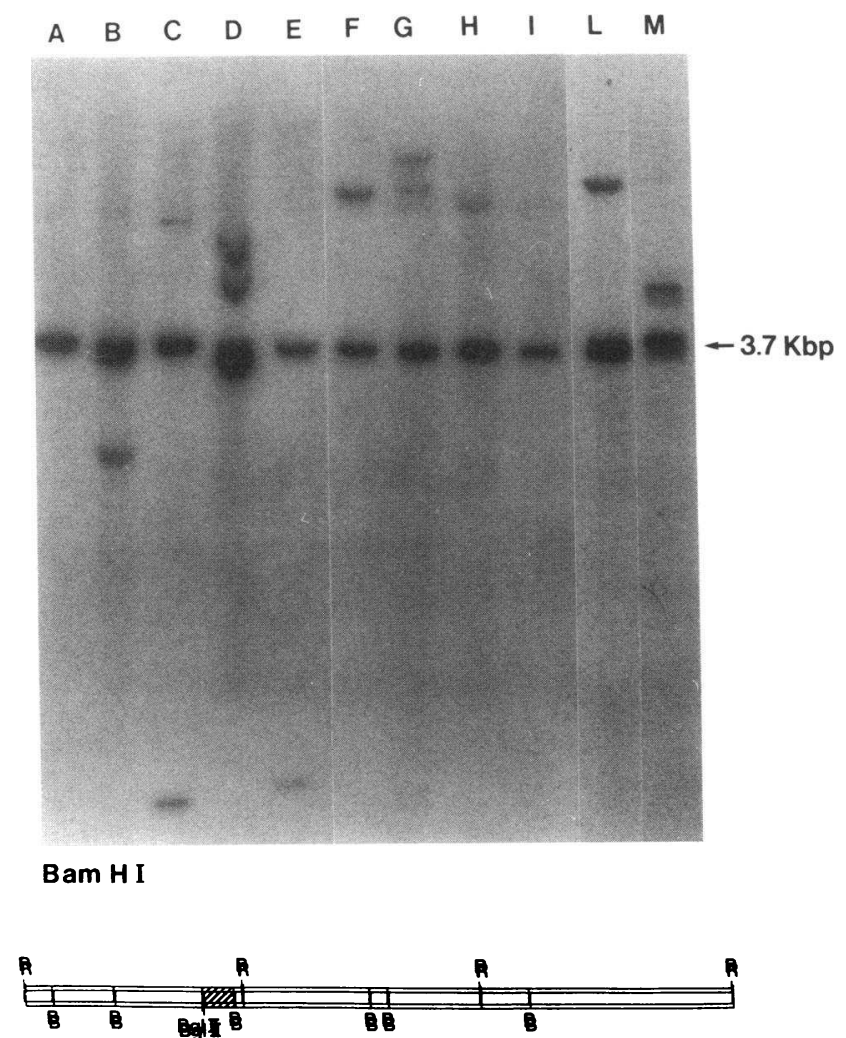

Figure 3. Examples of ret rearrangement in papillary thyroid carcinomas collected at the Mayo Clinic. (Lanes $B, C, D, E, F, G, H, L$, and $M$ ) DNAs extracted from different tumoral samples. (Lanes $A$ and $I$ ) DNA extracted from normal human tissue.
Table I. RET Acitvation in Human Thyroid Tumors

\begin{tabular}{|c|c|c|c|c|}
\hline \multirow[t]{2}{*}{ Tumor type } & \multicolumn{4}{|c|}{ Positive/analyzed } \\
\hline & USA & France & Italy & Total \\
\hline Papillary & $11 / 65$ & $8 / 70$ & $14 / 42$ & $33 / 177$ \\
\hline Follicular & $0 / 11$ & $0 / 13$ & $0 / 13$ & $0 / 37$ \\
\hline Anaplastic & $0 / 2$ & $0 / 5$ & $0 / 8$ & $0 / 15$ \\
\hline Medullary & $0 / 0$ & $0 / 3$ & $0 / 15$ & $0 / 18$ \\
\hline Adenoma & $0 / 0$ & $0 / 18$ & $0 / 16$ & $0 / 34$ \\
\hline${ }^{*}$ Other & $0 / 0$ & $0 / 1$ & $0 / 4$ & $0 / 5$ \\
\hline Total & 78 & 110 & 98 & 286 \\
\hline
\end{tabular}

* Squamous cell carcinoma, sarcomatoid carcinoma.

the samples, tested by the standard focus formation assay on $\mathrm{NIH} / 3 \mathrm{~T} 3$ cells, gave rise to transformed foci in $2-3 \mathrm{wk}$ (Table II). Also, the available metastases of the ret-positive tumors scored positive (Table II). Hybridization of the DNA extracted from the primary foci of transformed NIH/3T3 cells with retspecific probes allowed us to conclude that the transferred oncogene was actually an activated version of ret (data not shown). We also transfected the DNA extracted from nine follicular tumors; none gave rise to transformed foci (Table II).

Further characterization of gene rearrangement. We had previously reported that when tumors carrying an activated version of ret were probed with a $\mathrm{NH}_{2}$-terminal protoret-speci-

Table II. Transforming Activity of the Activated RET Oncogene from Papillary and Follicular Thyroid Carcinomas

\begin{tabular}{|c|c|c|c|c|}
\hline $\begin{array}{l}\text { Patient } \\
\text { No. }\end{array}$ & Histological type & Specimen $*$ & $\begin{array}{l}\text { Transforming } \\
\text { activity }^{\ddagger}\end{array}$ & $\begin{array}{c}\mathrm{H4} \\
\text { positivity }\end{array}$ \\
\hline 1 & Papillary Ca. & $\mathrm{T}$ & 0.05 & yes \\
\hline 1 & & $\mathbf{M}$ & 0.06 & yes \\
\hline 2 & & $\mathrm{~T}$ & 1.10 & yes \\
\hline 2 & & $\mathbf{M}$ & 0.03 & yes \\
\hline 3 & & $\mathrm{~T}$ & 0.10 & no \\
\hline 3 & & $\mathbf{M}$ & 0.30 & no \\
\hline 4 & & $\mathrm{~T}$ & 0.20 & yes \\
\hline 4 & & $\mathbf{M}$ & 0.03 & yes \\
\hline 5 & & $T$ & 0.07 & no \\
\hline 5 & & $\mathbf{M}$ & 0.10 & no \\
\hline 6 & & $\mathbf{M}$ & 0.05 & no \\
\hline 7 & & $\mathbf{T}$ & 0.35 & no \\
\hline 8 & & $\mathrm{~T}$ & 0.15 & yes \\
\hline 9 & & $T$ & 0.63 & no \\
\hline 9 & & $\mathbf{M}$ & 0.85 & no \\
\hline 10 & & $\mathrm{~T}$ & 0.31 & yes \\
\hline 11 & & $\mathbf{M}$ & 0.65 & yes \\
\hline 12 & & $\mathrm{~T}$ & 0.08 & no \\
\hline 12 & & $\mathbf{M}$ & 0.75 & no \\
\hline 13 & & $\mathbf{M}$ & 0.07 & yes \\
\hline 14 & & $T$ & 0.15 & no \\
\hline $15-24$ & Follicular Ca. & $T$ & $<0.003$ & no \\
\hline
\end{tabular}

* T, Primary tumor; M, Lymph nodal metastasis.

${ }^{\ddagger}$ NIH/3T3 Transformed foci/ $\mu$ g of DNA transfected. 


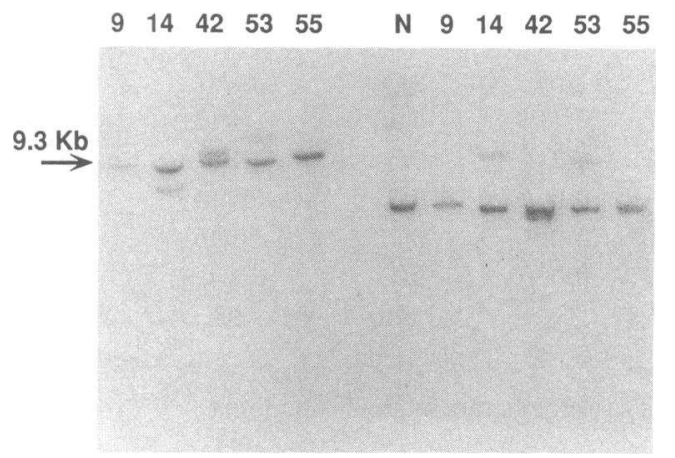

Hind III Eco RI

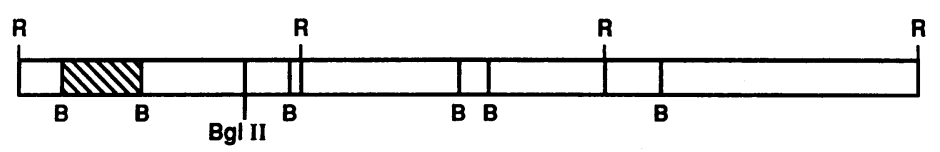

Figure 4. Rearrangement of the ret $5^{\prime}$ terminal region in papillary thyroid carcinomas. Southern blot analysis of DNA extracted from the neoplastic specimens. $10 \mu \mathrm{g}$ of DNA were hybridized to a 1.8-kbp DNA probe specific for the $5^{\prime}$ terminal region of the ret protooncogene. The arrows indicate the size of the normal fragment. A partial restriction map of the region of the ret gene analyzed and the probe used (shaded area) are shown. (Left) Samples collected at the Hospitals of Lyon. (Lanes 9, 10, 14, 42, 53, and 55) DNAs extracted from different tumoral samples. Lane $N$ : DNA extracted from normal human tissue. (Right) Samples collected at the Mayo Clinic. (Lanes $B, C, D, E, G$, $H, L$, and $M$ ) DNAs extracted from different tumoral samples. (Lane $N$ ) DNA extracted from normal human tissue. fic sequence, a rearranged band was also detectable. This suggests that the chromosomal event leading to ret activation should not involve deletion of its $\mathrm{NH}_{2}$-terminal encoding domain (13). Subsequently, we have demonstrated that an inversion (10) (q11.2-21) determined the H4-ret fusion in at least four cases of papillary thyroid carcinoma (17a). In the present study, we found that many of the samples also showed a similar mechanism. In fact, 10/11 samples from Mayo, 5/8 from Lyon, and 9/9 from Milan showed rearranged bands when probed with a 5'-terminal 1.8 -kbp ret-specific BamHI DNA fragment (probe 12 of Fig. 1) (Examples are shown in Fig. 4).

The PTC oncogene that we had isolated from papillary thyroid carcinomas by means of the transfection assay was shown to be the product of a fusion between a truncated ret gene and a novel sequence that we named H4 (13). We demonstrated that the truncation of the $\mathrm{H} 4$ gene could occur in different points over a sequence of several thousand base pairs (Fig. 1) (13). Thus, the analysis of $\mathrm{H} 4$ involvement has been performed by using different probes (shown in Fig. 1) from Alu-free regions of the $\mathrm{H} 4$ gene (probes 2, 8, 9, 10, 11, 3, of Fig. 1) (13). Fig. 5 shows the $\mathrm{H} 4$ gene rearrangement in the sample 14 from Lyon (probe 2 of Fig. 1) (13). We have shown $\mathrm{H} 4$ rearrangement also in one other sample that was collected at the Mayo Clinic (sample $D$ of Fig. 2) and cytogenetically showed a chromosome 10q inversion (14, 17a). Moreover, 7 out of the 14 samples which scored positive in the transfection assay showed $\mathrm{H} 4$ involvement, since in these cases the primary NIH/3T3 foci contained H4-specific sequences (Table II).

$R N A$ and PCR analysis. We have previously shown that ret rearrangement leading to PTC formation gives rise to truncated transcripts. The $\mathrm{H} 4$ promoter, which fuses to ret, is able to drive its expression in the thyroid tumor that carries the rearrangement. To increase the possibility of detecting the PTC formation, and to verify $\mathrm{H} 4$ involvement in the cases in which apparently by the Southern blot analysis $\mathrm{H} 4$ was not rearranged, we performed a PCR analysis on the RNA extracted from five ret-rearranged tumors. We copied $5 \mu \mathrm{g}$ of tumoral RNA by using reverse transcriptase and an antisense 18-bases long $3^{\prime}$ ret-specific oligonucleotide primer. We amplified the resultant cDNA with the same $3^{\prime}$ primer and a sense H4-specific 18-bases oligomer. An amplified 363-bp long fragment indicated the presence of a fused H4-ret transcript (i.e., activated PTC). The correct sized fragment was found in samples 10, 14, and 53 from Lyon, but not in samples 9 (Fig. 6) and 55 (not shown). Thus, in samples 10,14 , and 53 , ret was fused to $\mathrm{H} 4$; conversely in the samples 9 and 55 , the rearrangement of the ret protooncogene probably involved a gene distinct from $\mathrm{H} 4$.

\section{Discussion}

The identification of the nature of the genetic mutations in thyroid neoplasms, and the assessment of their prevalence in the various tumor phenotypes, is critical to an understanding
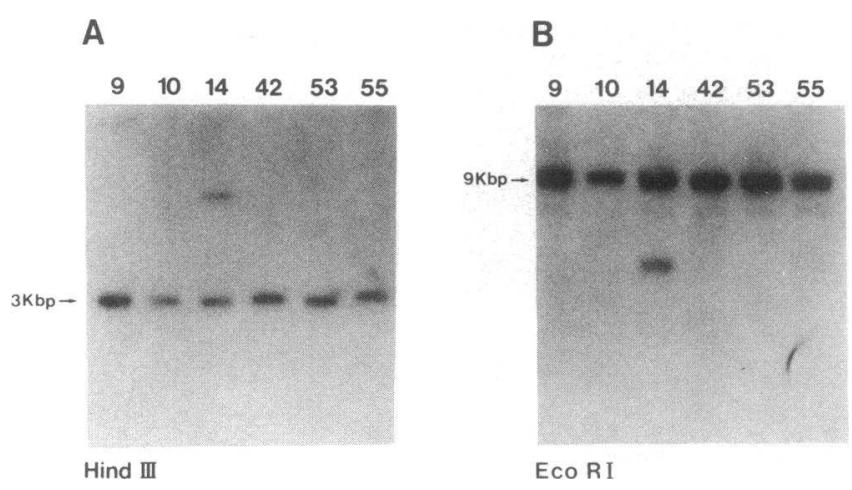

Figure 5. Rearrangement of $\mathbf{H} 4$ gene in one papillary thyroid carcinoma. Southern blot analysis of the DNAs extracted from the samples collected at the Hospitals of Lyon. The H4-specific DNA probe used is the probe 2 of reference 13 . The arrows indicate the sizes of the normal fragments. 

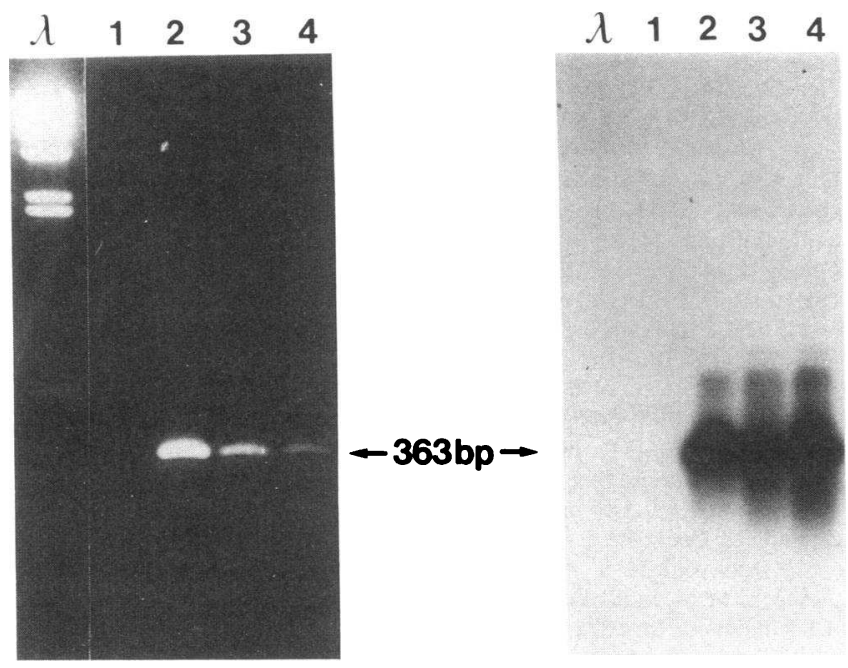

Figure 6. Expression in papillary thyroid carcinomas of a fused H4-ret transcript. PCR analysis on the RNA extracted from four papillary carcinomas collected at the Hospitals of Lyon. $5 \mu \mathrm{g}$ of total RNA were reverse transcribed using an antisense ret-specific oligonucleotide, and amplified using the same oligo together with an H4-specific amplimer. $1 / 10$ of the product of the amplification was subjected to electrophoretic separation on a $2 \%$ agarose gel. (Lanes 2, 3, and 4) RNA extracted from the patients 10,14 , and 53 of Fig. 1, respectively. (Lane 1) RNA extracted from patient 9. (A) Ethidium bromide staining of the agarose gel. $(B)$ Hybridization of the amplified product to a ret-specific cDNA probe (18).

of their pathogenesis. Different genetic events may occur to determine the different phenotypic characteristics of thyroid neoplasms, such as the ability to invade the lymphatics (papillary) or the blood vessels (follicular), or the propensity to become dedifferentiated (anaplastic).

We previously demonstrated the activation of the ret oncogene in papillary carcinomas $(12,13)$. To date, the ret-transforming gene has been found activated in vivo only in thyroid carcinomas (11-13) and in a papillary thyroid carcinoma cell line (24). Previously described rearrangements of the ret oncogene were found to have occurred in vitro during the transfection procedure (25-27). Moreover, we did not find any example of ret rearrangement by screening about 150 nonthyroid tumors (data not shown), and Ishizaka et al. have reported a similar result in a study of more than 100 nonthyroid tumors (28).

These published observations suggest that ret activation is specifically involved only in thyroid tumorigenesis, but they do not determine if a particular subtype of thyroid tumor has ret rearrangements. Therefore, we collected 286 human thyroid neoplastic samples and screened them by Southern blot analysis for ret rearrangement. We found ret activated only in the papillary subtype of these tumors: specifically, in 11 tumors collected at the Mayo Clinic, 8 collected at the Hospitals of Lyon, and 14 collected in Italy at the Istituto Nazionale Tumori of Milan and at the II Medical School of Naples. Our data strongly support the hypothesis that ret activation is specific for papillary carcinoma. In fact, none of either the 37 follicular carcinomas or the 72 other nonpapillary thyroid tumors scored positively.
Recently, Ishizaka et al. (29) published the detection of an activated ret (PTC) in 1 out of 11 thyroid papillary carcinomas, but also in 4 out of 19 follicular adenomas and in one of two adenomatous goiters. In the adenomas, however, the activation of ret was detected only in some regions of the tumors. They do not report any analysis of nonpapillary malignant tumors. Since the prevalence of occult thyroid carcinomas in the Japanese population is high, it is possible that the PTC-positive cases of follicular adenomas and adenomatous goiter could reflect a minor population of cancerous cells, as the authors suggest in their discussion.

We also noted a difference in the frequency of ret activation in different geographic areas, ranging from $11 \%$ in the French samples to $33 \%$ in the Italian samples. The U. S. tumors had an intermediate frequency of $17 \%$. This may suggest the involvement of different genetic or environmental factors in these three areas. The recent finding of high rates of ras codon 61 mutation in thyroid tumors in an iodide-deficient area (30), and the differences detected in the patterns of ras mutation between radiation-associated and spontaneous human thyroid carcinomas (31) seem to support such suggestion. It is noteworthy that only one of the patients positive for ret activation in this study, had a prior documented radiation exposure.

We have also been able to demonstrate that the $\mathrm{H} 4$ gene was involved in ret activation in 11 out of 33 ret rearranged samples. We demonstrated this involvement in two cases by Southern blot analysis (samples 14 and D), in three cases by PCR analysis (samples 10, 53, and again, 14), and in seven cases (Milan samples) by the transfection assay. We cannot exclude, however, that $\mathrm{H} 4$ may be involved in the remaining cases because we did not have enough RNA and DNA to perform PCR or transfection assays, respectively, in the apparently negative samples. In at least 5 of these 22 cases we have conclusively demonstrated that ret is not fused to $\mathrm{H} 4$, and still other uncharacterized genes may be involved in the rearrangement. Interestingly, cytogenetic studies of papillary carcinoma have demonstrated that the region where ret is mapped (10q11.2) is also involved in translocations with other chromosomes (14).

In 24 of 33 ret-rearranged cases, the 5 terminal region of the ret gene (extracellular and transmembrane encoding region) was not deleted, but was present rather in a rearranged status, similar to previously described cases (13).

There still remain major unanswered questions about the manner in which thyroid tumors evolve, and the molecular events that determine whether a tumor behaves either as a differentiated papillary/follicular or as a dedifferentiated anaplastic one. Other genetic alterations are frequently detected in thyroid tumors and include mutations involving ras genes. However, the published studies on ras oncogene involvement (30-36) indicate a significant heterogeneity among the results obtained by different groups. Whereas ras point mutations are present with an about equivalent frequency in both benign and malignant thyroid tumors, the same conclusion is not readily established when the follicular and papillary types are compared. We have previously demonstrated that the oncogene trk, belonging to the tyrosine kinase family, is also frequently (about $10 \%$ ) activated in papillary carcinomas (12), and recently, Suarez et al. (37) observed $g s p$ mutations in $\sim 10 \%$ of differentiated thyroid carcinomas. In addition, allelic loss studies of chromosome 3 and 10 have demonstrated differences between papillary and follicular carcinomas (38). These data 
indicate that other somatic mutations should be considered to explain the differing behavior patterns exhibited by different thyroid tumor types. However, from our studies we would suggest that ret activation represents an important and apparently specific genetic event in the development of human papillary thyroid carcinoma.

\section{Acknowledgments}

We acknowledge the assistance of Dr. S. Pilotti in obtaining the tumor samples from the Istituto Nazionale Tumori, and we are also grateful to Dr. C. S. Grant in obtaining the tumor samples from patients operated at Rochester Methodist Hospital. We also acknowledge the contribution of Dr. V. N. Patel who performed many of the DNA extractions from the Mayo Clinic material. Finally, the authors are indebted to $F$. D'Agnello, F. Moscato, and M. Berardone for the art work.

This work has been supported by the Progetto Finalizzato "Ingegneria Genetica" and the Progetto Finalizzato "Biotecnologia e Biostrumentazione" of the CNR, by the "Progetto AIDS" of the Istituto Superiore di Sanità, by grants from the Associazione Italiana Ricerca sul Cancro, and also by a grant from La Ligue contre le Cancer du Rhone.

\section{References}

1. Weinberg, R. 1989. Oncogenes, antioncogenes and the molecular bases of multistep carcinogenesis. Cancer Res. 49:3713-3721.

2. Klein, G. 1987. The approaching era of the tumor suppressor genes. Science (Wash.). 238:1539-1545.

3. Bishop, J. M. 1987. The molecular genetics of cancer. Science (Wash. DC). 235:305-311.

4. Seeger, R. C., G. M. Brodeur, and H. Sather. 1985. Association of multiple copies of the N-myc oncogene with rapid progression of neuroblastomas. $N$. Engl. J. Med. 313:1111-1116.

5. Slamon, D. J., W. Godolphin, L. A. Jones, J. A. Holt, S. G. Wong, D. E. Keith, W. J. Levin, S. G. Stuart, J. Udove, A. Ullrich, et al. 1989. Studies of the Her-2/neu proto-oncogene in human breast and ovarian cancer. Science (Wash.). 244:707-712.

6. Bos, J. L., E. R. Fearon, S. R. Hamilton, M. Verlaan de Vries, J. H. van Boom, A. J. van der EB, and B. Vogelstein. 1987. Prevalence of ras gene mutations in human colorectal cancers. Nature (Lond.) 327:293-297.

7. Almoguera, C., D. Shibata, K. Forrester, J. Martin, N. Arnheim, and M. Perucho. 1988. Most human carcinomas of the exocrine pancreas contain mutant K-ras genes. Cell. 53:549-554.

8. Rodenhuis, S., R. J. C. Slebos, A. J. M. Boot, S. G. Evers, W. J. Mooi, S. S. Wagenaar, P. C. Van Bogedom, and J. L. Bos. 1988. Incidence and possible clinical significance of K-ras oncogene activation in adenocarcinoma of the human lung. Cancer Res. 48:5738-5741.

9. Farr, C. J., R. K. Saiki, H. A. Erlich, F. McCormich, and C. J. Marshall. 1988. Analysis of ras gene mutation in acute myeloid leukemia by polymerase chain reaction and oligonucleotide probes. Proc. Natl. Acad. Sci. USA. 85:16291633.

10. Williams ED. 1980. Recent Results in Cancer Research: Thyroid Cancer. W. Duncan, editor. Springer-Verlag, Berlin. 47-55.

11. Fusco, A., M. Grieco, M. Santoro, M. T. Berlingieri, S. Pilotti, M. A. Pierotti, G. Della Porta, and G. Vecchio. 1987. A new oncogene in human papillary carcinomas and their lymph-nodal metastases. Nature (Lond.). 328:170-172.

12. Bongarzone, I., M. A. Pierotti, N. Monzini, P. Mondellini, G. Manenti, R. Donghi, S. Pilotti, M. Grieco, M. Santoro, A. Fusco, et al. 1989. High frequency of oncogene activation in human thyroid papillary carcinomas. Oncogene. $4: 1457-1462$.

13. Grieco, M., M. Santoro, M. T. Berlingieri, R. M. Melillo, R. Donghi, I. Bongarzone, M. A. Pierotti, G. Della Porta, A. Fusco, and G. Vecchio. 1990. PTC is a novel rearranged form of the ret proto-oncogene and is frequently detected in vivo in human thyroid papillary carcinomas. Cell. 60:557-563.

14. Jenkins, R. B., I. D. Hay, J. F. Herath, C. G. Schultz, J. L. Spurbeck, C. S. Grant, J. R. Goellner, and G. W. Dewald. 1990. Frequent occurrence of cytogenetic abnormalities in sporadic nonmedullary thyroid carcinoma. Cancer (Phila.). 66:1213-1220.

15. Donghi, R., G. Sozzi, M. A. Pierotti, I. Biunno, M. Miozzo, A. Fusco, M. Grieco, M. Santoro, G. Vecchio, N. K. Spurr, et al. 1989. The oncogene asso- ciated to human thyroid papillary carcinoma (PTC) maps to a region on chromosome 10 linked to multiple endocrine neoplasia type 2A (MEN 2A). Oncogene. 4:321-323.

16. Sozzi, G., M. A. Pierotti, R. Donghi, M. Miozzo, P. Radice, M. Grieco, M. Santoro, A. Fusco, G. Vecchio, C. Matthew, et al. 1991. Refined localization to contiguous regions of chromosome $10 \mathrm{q}$ of the two genes (H4 and RET) that form the oncogenic sequence PTC. Oncogene. 6:339-342.

17. Ishizaka Y., F. Itoh, T. Tahira, I. Ikeda, T. Sugimura, J. Tucker, A. Fertitta, A. V. Carrano, and M. Nagao. 1989. Human ret proto-oncogene mapped to chromosome 10q11.2. Oncogene. 4:1519-1521.

17a. Pierotti, M. A., M. Santoro, R. B. Jenkins, G. Sozzi, I. Bongarzone, M. Grieco, N. Monzini, M. Miozzo, M. A. Herrmann, A. Fusco, et al. 1992. Characterization of an inversion on the long arm of chromosome 10 juxtaposing RET and D10S170 and creating the oncogenic sequence RET/PTC. Proc. Natl. Acad. Sci. USA. 89:1616-1620.

18. Sambrook, J., E. F. Fritsch, and T. Maniatis. 1989. Molecular Cloning: A Laboratory Manual. Cold Spring Harbor Laboratory Press, New York. 545 pp.

19. Santoro, M., R. Rosati, M. Grieco, M. T. Berlingieri, L. Colucci-D'Amato, V. De Franciscis, and A. Fusco. 1990. The ret proto-oncogene is consistently expressed in human pheochromocytomas and thyroid medullary carcinomas. Oncogene. 5:1595-1598.

20. Kawasaki, E. S. 1990. A guide to methods and applications. In PCR protocols. M. A. Innis, D. H. Gelfand, J. J. Sninsky, and T. J. White editors. Academic Press, Inc., San Diego. 21-38.

21. Takahashi, M., and G. M. Cooper. 1987. Ret transforming gene encodes a fusion protein homologous to tyrosine kinases. Mol. Cell. Biol. 7:1378-1385.

22. Takahashi M., Y. Buma, T. Iwamoto, Y. Inaguma, H. Ikeda, and H. Hiai. 1988. Cloning and expression of the ret proto-oncogene encoding a tyrosine kinase with two potential transmembrane domains. Oncogene. 3:571-578.

23. Takahashi, M., Y. Buma, and H. Hiai. 1989. Isolation of ret proto-oncogene cDNA with an aminoterminal signal sequence. Oncogene. 4:805-805.

24. Ishizaka Y., F. Itoh, T. Tahira, I. Ikeda, T. Ogura, T. Sugimura, and M. Nagao. 1989. Presence of aberrant transcripts of ret proto-oncogene in a human papillary thyroid carcinoma cell line. Jpn. J. Cancer Res. 80:1149-1152.

25. Takahashi M., Y. Inaguma, H. Hiai, and F. Hirose. 1988. Developmentally regulated expression of a human "finger" containing gene encoded by the 5 ' half of the ret transforming gene. Mol. Cell. Biol. 8:1853-1856.

26. Ishizaka Y., M. Ochiai, T. Tahira, T. Sugimura, and M. Nagao. 1989 Activation of the ret-II oncogene without a sequence encoding a transmembrane domain and transforming activity of two ret-II oncogene products differing in carboxy-termini due to alternative splicing. Oncogene. 4:789-794.

27. Koda, T. 1988. Ret gene from a human stomach cancer. Hokkaido J. Med. Sci. 63:913-924.

28. Ishizaka, Y., T. Ushijima, T. Sugimura, and M. Nagao. 1990. cDNA cloning and characterization of ret activated in a human papillary thyroid carcinoma cell line. Biochem. Biophys. Res. Commun. 168(2):402-408.

29. Ishizaka, Y., S. Kobayashi, T. Ushijima, S. Hirohashi, T. Sugimura, and M. Nagao. 1991. Detection of retTPC/PTC transcripts in thyroid adenomas and adenomatous goiter by an RT-PCR method. Oncogene. 6:1667-1672.

30. Shi, Y., M. Zou, H. Schmidt, F. Juhasz, V. Stensky, D. Robb, and N. R. Farid. 1991. High rates of ras codon 61 mutation in thyroid tumors in an iodidedeficient area. Cancer Res. 51:2690-2693.

31. Wright, P. A., E. D. Williams, N. R. Lemoine, and D. Wynford-Thomas. 1991. Radiation-associated and "spontaneous" human thyroid carcinomas show a different pattern of ras oncogene mutation. Oncogene. 6:471-473.

32. Lemoine, N. R., E. S. Mayall, F. S. Wyllie, E. D. Williams, M. Goyns, B. Stringer, and D. Wynford-Thomas. 1989. High frequency of ras oncogene activation in all stages of human thyroid tumorigenesis. Oncogene. 4:159-164.

33. Lemoine, N. R., E. S. Mayall, F. S. Wyillie, C. J. Farr, D. Hughes, R. A. Padua, V. Thurston, E. D. Williams, and D. Wynford-Thomas. 1988. Activated ras oncogenes in human thyroid cancers. Cancer Res. 48:4459-4463.

34. Suarez, H. G., J. A. du Villard, M. Severino, B. Caillou, M. Schlumberger, M. Tubiana, C. Parmentier, and R. Monier. 1990. Presence of mutations in all three ras genes in human thyroid tumors. Oncogene. 5:565-570.

35. Namba, H., R. A. Gutman, K. Matsuo, A. Alvarez, and J. A. Fagin. 1990. H-Ras proto-oncogene mutation in human thyroid neoplasms. J. Clin. Endocrinol. Metab. 71:223-229.

36. Namba, H., S. A. Rubin, and J. A. Fagin. 1990. Point mutations of ras oncogenes are an early event in thyroid tumorigenesis. Mol. Endocrinol. 4:1474 1479.

37. Suarez, H. G., J. A. du Villard, B. Caillou, M. Schlumberger, C. Parmentier, and R. Monier. 1991. Gsp mutations in human thyroid tumours. Oncogene. 6:677-679.

38. Herrmann, M. A., I. D. Hay, D. H. Bartett, S. R. Ritland, R. J. Dahl, C. S. Grant, and R. B. Jenkins. 1991. Cytogenetic and molecular genetic studies of follicular and papillary thyzoid carcinomas. J. Clin. Invest. 88:1596-1604. 